\title{
ASSESSMENT OF A SELF-REPORTED DRINKS DIARY FOR THE ESTIMATION OF DRINKS INTAKE BY CARE HOME RESIDENTS: FLUID INTAKE STUDY IN THE ELDERLY (FISE)
}

\author{
F.O. JIMOH, D. BUNN, L. HOOPER \\ Norwich Medical School, University of East Anglia, Norwich Research Park, Norwich NR4 7TJ, Norfolk, UK. Corresponding author: Florence O Jimoh, 3 Ambleside, Hethersett, \\ Norwich. NR9 3PN. Phone +44 (0)7733389801, Email fjimoh2011@gmail.com
}

\begin{abstract}
Objectives: We evaluated the accuracy of a newly developed self-completed Drinks Diary in care home residents and compared it with direct observation and fluid intake charts. Design: Observational study. Setting: Residential care homes in Norfolk, UK. Participants: 22 elderly people (18 women, mean age 86.6 years SD 8.6, 12 with MMSE scores <27). Measurements: Participants recorded their own drinks intake over 24 hours using the Drinks Diary while care staff used the homes' usual fluid intake chart to record drinks intake. These records were compared with drinks intake assessed by researcher direct observation (reference method), during waking hours (6am to $10 \mathrm{pm}$ ), while drinks taken from $10 \mathrm{pm}$ to $6 \mathrm{am}$ were self-reported and checked with staff. Results: Drinks intake assessed by the Drinks Diary was highly correlated with researcher direct observation (Pearson correlation coefficient $\mathrm{r}=0.93, \mathrm{p}<0.001$, mean difference $-163 \mathrm{ml} /$ day) while few staff-completed fluid charts were returned and correlation was low ( $\mathrm{r}=0.122, \mathrm{p}=0.818$, mean difference $702 \mathrm{ml} /$ day). The Drinks Diary classified 19 of 22 participants correctly as drinking enough or not using both the European Food Safety Authority and US recommendations. Conclusion: The Drinks Diary estimate of drinks intake was comparable with direct observation and more accurate (and reliably completed) than staff records. The Drinks Diary can provide a reliable estimate of drinks intake in elderly care home residents physically and cognitively able to complete it. It may be useful for researchers, care staff and practitioners needing to monitor drinks intake of elderly people, to help them avoid dehydration.
\end{abstract}

Key words: Nutrition surveys, homes for the aged, beverages, dehydration, aged.

\section{Introduction}

Water-loss dehydration, due to inadequate fluid intake, is common in long-term care $(1,2)$, and associated with doubled risk of 4-year disability and a $40 \%$ increase in 8 -year mortality in US elders (3). In the UK, the Dehydration Recognition In our Elders (DRIE) study (4) found that $20 \%$ of care home residents were dehydrated (serum osmolality $>300 \mathrm{mOsm} /$ $\mathrm{kg}$ ) (5). A prospective US study reported $31 \%$ of nursing home residents to be dehydrated at some point over six months (6) and a US cross-sectional study found that $98 \%$ of residents consumed less than 1.5L/day (1). Limitations such as disability, impaired cognition, reduced swallowing capacity and fear of incontinence increase the risk of low fluid intake (7) (8). Monitoring drinks intake in elderly care home residents could help identify those at risk of dehydration, facilitating appropriate interventions (7).

Fluid balance charts (a record of fluid intake and output) or drinks intake charts (record of drinks only) may be used by hospital and care staff to document fluid or drinks intake. Several studies have reported inaccuracies of such charts, especially in residential homes $(1,9,10)$. In one study, onethird of residents whose fluid intake placed them at risk of dehydration were not identified (1). There is a need to ensure accurate documentation or find alternative methods of monitoring drinks intake.

Our aim was to assess the accuracy of a drinks self-recording tool (Drinks Diary) for use by elderly people living in care homes and to compare its results with researcher observation as the reference standard. We also compared Drinks Diary results with staff-completed drinks intake charts when available.

\section{Methods}

The Fluid Intake Study in the Elderly (FISE) was a partnerstudy of DRIE. The Drinks Diary was developed following several rounds of piloting and modifications of earlier versions with older people living in the community, the researchers' family members and a DRIE Resident Advisory Group, until there were no further suggestions to address. Criteria for its development were that it be easily understood and completed with minimal writing. The Drinks Diary (with instructions for calculating volume of drinks consumed, and adequacy of drinks intake) is freely available to download (from http://www. uea.ac.uk/medicine/research/research-evidence-studies/drinksdiary). The Faculty of Medicine and Health Sciences Research Ethics Committee, University of East Anglia (2012/2013-47, April 2013) provided ethical approval.

\section{Study Participants}

Care home residents aged $\geq 65$ years in Norfolk (UK), who had provided their own informed consent for DRIE and had a Mini Mental State Examination (MMSE, which scores from 0 to 30 , with higher scores indicating better cognition (11)) 
score $\geq 20$ were eligible. DRIE participants did not have renal or congestive cardiac failure (according to care staff), and were not receiving palliative care. Further written informed consent was obtained from all FISE participants, and included permission to access data on age, weight, height, cognitive ability, mobility, self-care and functional status (part of the Barthel Index (12)) and quality of life (EuroQol [5D 3L] (13)) collected for DRIE.

\section{Assessment of Drinks Intake by the Drinks Diary and Direct Observation}

Each FISE participant completed the Drinks Diary for 24 hours (one day), noting for each drink the time of drinking, what was drunk, cup type and proportion drunk. To complete the Drinks Diary, participants were instructed to start at $10 \mathrm{pm}$ one day and finish at $10 \mathrm{pm}$ the next day. Each time a drink was taken (alone, with food or with pills), they would write in the name of the drink, tick the type of mug, cup or glass used, and tick the picture that showed how much they drank (a little, half, a lot or all). An example showed someone taking half a small glass of milk with their pills.

The researcher spent time explaining how to complete the Drinks Diary, including having a drink with the resident and asking them to complete a copy of the Drinks Diary appropriately for that drink. She provided a lightweight clip board and a large grip pen to aid the completion.

During the same 24 hours a researcher directly and continuously observed drinks intake (one observer for each participant), weighing (Electronic Kitchen Scale made by WeiHeng Electronic Scale Ltd. Model: WH-BO5. Range 0.1g$1 \mathrm{~kg}$ ) and recording vessel and drink offered to and returned by residents during waking hours (6am to $10 \mathrm{pm})$. Participants and night staff were asked about any drinks taken from $10 \mathrm{pm}$ to 6am. All drinks served at meal and non-meal times (water, flavoured water, milk, flavoured milk, fruit juice, squashes, tea, coffee, drinking chocolate, wine, beer, spirits, liquid supplements and drinks given with medications) were recorded. Participants and staff were fully informed that we were assessing how well the Drinks Diary assessed drinks intake.

Total volume of drinks consumed as assessed using the Drinks Diary was calculated by a researcher not involved in (and blinded to) the observation, based on the information provided on the diary. They assumed that 'a little' represented one-quarter of the capacity of the type of glass, mug or cup, 'half' was half, 'most' was three-quarters and 'all' represented $100 \%$ consumption (this was based on the underlying assumptions in setting up the diary and due to the scale of the study was not tested before the Drinks Diary was formally assessed). When proportions drunk were not indicated, the researcher assumed all was consumed. Staff members were asked to complete the care homes' own fluid intake chart for the included participant during the same 24 hours. The Drinks Diary and fluid intake charts were measured in $\mathrm{ml} / 24$ hours (we assumed $1 \mathrm{~g}=1 \mathrm{ml}$ for all drinks).

\section{Statistical analysis}

Data were analysed using SPSS, version 18 and normality evaluated (Shapiro-Wilk test) (14). Pearson's correlation coefficient and Bland-Altman regression were used to assess association between Drinks Diary and direct observation intakes, p-values were two-tailed $(15,16)$. Pearson's correlation coefficient was used to assess the association between the staff assessments using the homes' fluid intake charts and the corresponding direct observation. Participants' observed fluid intakes were compared with European Food Safety Authority's (EFSA's) recommendation of 1.6L/day of drinks for women and 2.0L/day for men (based on EFSA's assumption that beverages contribute $80 \%$ of fluid intake (17)) and the Institute of Medicine's (IOM's) (18) recommendation for adequate drinks intake of $2.2 \mathrm{~L} /$ day for women and $3.0 \mathrm{~L} / \mathrm{day}$ for men.

\section{Results}

\section{Recruitment of Participants}

Sixty two DRIE participants lived in care homes where FISE was carried out, but 30 were not approached due to stroke or Parkinson's disease (limiting writing, 3 participants), blindness, (1 participant), low MMSE (5 participants), being very ill (6 participants), hospital admission (1 participant), having had consultee consent for DRIE, rather than providing their own informed consent (7 participants), moved from the care home (3 participants) or died between their participation in DRIE and recruitment for the FISE study (4 participants). Ten of the 32 participants approached declined to take part (four did not feel well enough, four were not interested, one was illiterate, one did not provide a reason). Twenty two care home residents consented, and all completed the Drinks Diary (although four had one or more problems completing their diaries: one failed to indicate amount drunk on one occasion, two failed to indicate type of vessel on one occasion each and one participant (MMSE score of 22) did not indicate proportions drunk at all). Eight fluid charts were returned by care home staff, two were non-quantitative.

\section{Participant Characteristics}

Participants were aged 68 to 100 years, 16 of the 22 were female, two were underweight (BMI <18.5), two were obese (BMI $\geq 30)$ (Table 1). MMSE scores ranged from 13 to 30, 10 participants had normal cognitive function (MMSE Score $\geq 27$ ) (11) and two had an MMSE score $<20$ (wrongly included due to blinding, however, they both completed the Drinks Diary well and are included in analyses) .

\section{Comparing the Drinks Diary with Direct Observation}

Drinks Diary mean drinks intake was 1989g/day (SD 758), compared to $1826 \mathrm{~g} /$ day (SD 721, both normally distributed) by direct observation, mean difference $-163 \mathrm{~g} /$ day, $95 \% \mathrm{CI}$ : $-342,16, p=0.073$. In sensitivity analysis (excluding two 
Table 1

Baseline characteristics of the participants

\begin{tabular}{|c|c|c|c|c|c|c|c|c|}
\hline Participants' ID & MMSE Score\# & Age (years) & BMI Kg/m 2 & Barthel Index Score* & Mobility & Continence & Toilet use & Usual Activities \\
\hline F6 & 13 & 78 & 31.3 & 95 & 2 & 2 & 2 & 1 \\
\hline F7 & 14 & 73 & 24.6 & 95 & 2 & 2 & 2 & 1 \\
\hline $\mathrm{F} 4$ & 20 & 86 & 24.1 & 75 & 2 & 2 & 2 & 1 \\
\hline M2 & 22 & 87 & 16.5 & 75 & 2 & 2 & 2 & 2 \\
\hline F15 & 22 & 100 & 27.9 & 85 & 2 & 1 & 2 & 2 \\
\hline F16 & 23 & 78 & 29.6 & 30 & 0 & 0 & 1 & 3 \\
\hline F10 & 24 & 86 & 24.0 & 45 & 1 & 1 & 1 & 3 \\
\hline F8 & 25 & 68 & 28.8 & 100 & 2 & 2 & 2 & 1 \\
\hline M5 & 25 & 89 & 26.5 & 80 & 2 & 2 & 2 & 1 \\
\hline M6 & 25 & 93 & 20.1 & 55 & 1 & 1 & 1 & 1 \\
\hline F13 & 25 & 90 & 17.7 & 85 & 2 & 2 & 2 & 3 \\
\hline M4 & 26 & 71 & 31.4 & 10 & 0 & 0 & 0 & 1 \\
\hline F5 & 27 & 93 & 21.7 & 95 & 2 & 2 & 2 & 1 \\
\hline M3 & 27 & 83 & 19.1 & 95 & 2 & 2 & 2 & 1 \\
\hline F9 & 27 & 93 & 22.0 & 90 & 2 & 2 & 2 & 2 \\
\hline F14 & 27 & 92 & 23.5 & 85 & 2 & 2 & 2 & 1 \\
\hline F3 & 28 & 99 & 24.8 & 90 & 2 & 2 & 2 & 2 \\
\hline F11 & 28 & 90 & 21.9 & 95 & 2 & 2 & 2 & 2 \\
\hline F12 & 28 & 86 & 29.2 & 95 & 2 & 2 & 2 & 1 \\
\hline $\mathrm{F} 2$ & 29 & 83 & 24.3 & 75 & 2 & 1 & 2 & 2 \\
\hline M1 & 29 & 93 & 27.5 & 100 & 2 & 2 & 2 & 1 \\
\hline $\mathrm{F} 1$ & 30 & 94 & 19.7 & 95 & 2 & 1 & 2 & 1 \\
\hline Mean \pm SD & $24.7 \pm 4.3$ & $86.6 \pm 8.6$ & $24.4 \pm 4.3$ & $79.3 \pm 23.9$ & & & & \\
\hline
\end{tabular}

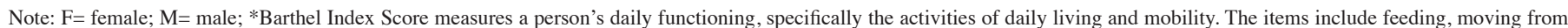

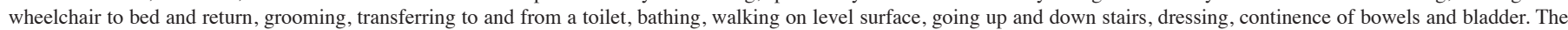

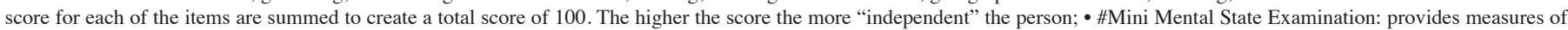

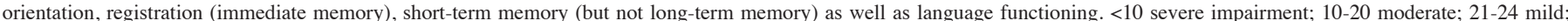

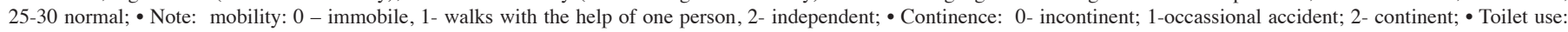
1-dependent; 2 - needs help but can do something themselves; 3 - independent; • Usual activities: 1 - no problems; 2- some problems; 3 - unable

participants with MMSE <20) mean difference was -184 g/day, 95\% CI: $-12,380, \mathrm{p}=0.065$.

The Pearson correlation coefficient between direct observation and Drinks Diary indicated good reliability $(\mathrm{r}=0.851, \mathrm{p}<0.001$, or excluding those with MMSE $<20$ $\mathrm{r}=0.844, \mathrm{p}<0.001)$ and based on Bland-Altman's regression analysis, most differences were within 2 standard deviations (there was one outlier, see Figure 1). By contrast, the Pearson correlation coefficient between direct observation and the staffs' fluid intake chart was low $(r=0.122, p=0.818)$. Sixteen participants overestimated drinks intake using the Drinks Diary, compared to direct observation, while six underestimated. Overestimation was mainly due to participants indicating greater proportions of drinks consumed than direct observation while underestimation was due to whole drinks being missed in the Drinks Diary.

The Drinks Diary classified 19 of 22 participants correctly as meeting or not meeting EFSA recommendations (17) (Table 2 ). The three incorrectly classified had overestimated their drinks intake using the Drinks Diary. For one participant amounts drunk were not reported, so the assessor assumed all was drunk (the estimate would have been improved if the assessor assumed' half' rather than 'all' was drunk where no proportion was given). For the others, overestimation in Drinks Diaries was due to participants' perception of proportions consumed. Similarly, the Drinks Diary classified 19 of 22 participants correctly as meeting or not meeting the IOM recommended intakes. The three who were not correctly classified had overestimated their drinks intake (Table 2).

\section{Comparing Staff completed drinks intake chart with Direct} Observation

Although we requested fluid intake charts be completed by care home staff for all twenty two participants, only 
Table 2

Drinks intake as assessed by the three different methods, plus the European and US drinks intake standards

\begin{tabular}{|c|c|c|c|c|c|c|c|}
\hline Participants' ID & $\begin{array}{c}\text { Correctly } \\
\text { completed the } \\
\text { Drinks Diary }\end{array}$ & $\begin{array}{c}\text { Drinks intake by } \\
\text { the Drinks Diary } \\
\mathrm{ml} / 24 \mathrm{hrs}\end{array}$ & $\begin{array}{c}\text { Drinks intake by } \\
\text { direct observa- } \\
\text { tion } \mathrm{ml} / 24 \text { hrs }\end{array}$ & $\begin{array}{c}\text { Difference } \\
\text { between Drinks } \\
\text { Diary and Direct } \\
\text { observation } \\
(\mathrm{ml} / 24 \mathrm{hrs})\end{array}$ & $\begin{array}{l}\text { Staff assessment } \\
\text { of drinks intake } \\
\text { by fluid intake } \\
\text { chart (ml/24 hrs) }\end{array}$ & $\begin{array}{c}\text { EFSA standard } \\
\text { ml/day }\end{array}$ & $\begin{array}{l}\text { IOM standard } \\
\text { ml/day }\end{array}$ \\
\hline F6 & Yes & 1163 & $1159 * \wedge$ & -4 & NR & 1600 & 2200 \\
\hline F7 & Yes & 1444 & $1536^{* \wedge}$ & 92 & NR & 1600 & 2200 \\
\hline $\mathrm{F} 4$ & Yes & 1397.5 & $1097 * \wedge$ & -300.5 & NR & 1600 & 2200 \\
\hline M2 & $\begin{array}{l}\text { Partly, type of } \\
\text { vessel indicated, } \\
\text { but amount drunk } \\
\text { not indicated } \\
\text { at all }\end{array}$ & 2754 & $1254^{* \wedge}$ & -1500 & NR & 2000 & 3000 \\
\hline F15 & Yes & 2048 & 2049 & 1 & NR & 1600 & 2200 \\
\hline F16 & Yes & 982.5 & $1101^{* \wedge}$ & 118.5 & NR & 1600 & 2200 \\
\hline F10 & $\begin{array}{c}\text { Mostly, type } \\
\text { of vessel not } \\
\text { indicated on one } \\
\text { occasion }\end{array}$ & 1742.5 & $1715^{\wedge}$ & -27.5 & NR & 1600 & 2200 \\
\hline F8 & $\begin{array}{l}\text { Mostly, amount } \\
\text { drunk not } \\
\text { indicated on two } \\
\text { occasions }\end{array}$ & 2346 & $1513 * \wedge$ & -833 & NR & 1600 & 2200 \\
\hline M5 & Yes & 2868 & 2698 & -170 & NR & 2000 & 3000 \\
\hline M6 & Yes & 917 & $810 * \wedge$ & -107 & NR & 2000 & 3000 \\
\hline F13 & Yes & 1103.25 & $1033^{* \wedge}$ & -70.25 & 1325 & 1600 & 2200 \\
\hline M4 & Yes & 2021.75 & $1970 * \wedge$ & -51.25 & 2210 & 2000 & 3000 \\
\hline F5 & yes & 1877.5 & $1600^{\wedge}$ & -277.5 & NR & 1600 & 2200 \\
\hline M3 & $\begin{array}{c}\text { Mostly, type } \\
\text { of vessel not } \\
\text { indicated on one } \\
\text { occasion }\end{array}$ & 3154.5 & $2825^{\wedge}$ & -329.5 & 1400 & 2000 & 3000 \\
\hline F9 & Yes & 1638.25 & $1887^{\wedge}$ & 248.75 & 860 & 1600 & 2200 \\
\hline F14 & Yes & 1355.75 & $1393 * \wedge$ & 37.25 & NR & 1600 & 2200 \\
\hline F3 & Yes & 1737.5 & $1601^{\wedge}$ & -136.5 & NR & 1600 & 2200 \\
\hline F11 & Yes & 1987 & $1942^{\wedge}$ & -45 & 612 & 1600 & 2200 \\
\hline F12 & Yes & 1729 & $1721^{\wedge}$ & -8 & 762 & 1600 & 2200 \\
\hline $\mathrm{F} 2$ & Yes & 2957.5 & 3403 & 445.5 & NR & 1600 & 2200 \\
\hline M1 & Yes & 3315 & $2645^{\wedge}$ & -670 & NR & 2000 & 3000 \\
\hline F1 & Yes & 3217.5 & 3218 & 0.5 & NR & 1600 & 2200 \\
\hline Mean \pm SD & & $1989.0 \pm 757.8$ & $1825.9 \pm 721.3$ & $-163.1 \pm 404.6$ & $1194.8 \pm 588.0$ & & \\
\hline
\end{tabular}

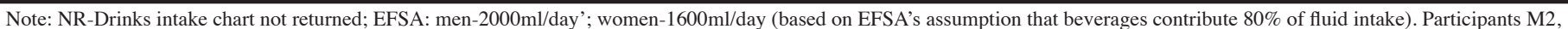

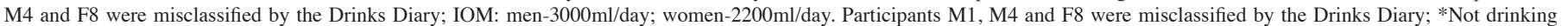
enough by EFSA standard; ^ Not drinking enough by IOM standard

eight were returned. Of these six were quantitative while the other two were reported in non-quantitative ways such as 'two cups of tea', so could not be included in analyses. The mean difference between direct observation and the staff-completed fluid chart was $702 \mathrm{~g} /$ day $(\mathrm{p}=0.076$, with low correlation $\mathrm{r}=0.122, \mathrm{p}=0.818$ ). Four of the six quantitative fluid intake charts underestimated intake, sometimes because staff stopped recording several hours before the last drink and sometimes because drinks were only recorded at meal and tea trolley times. In all cases, staff recorded how much drink residents were given, not how much they drank. The staffcompleted fluid intake chart correctly classified only one of six 


\section{JNHA: NUTRITION}

participants as meeting/not meeting the EFSA guidelines, but was correct for all six for IOM guidance (as the IOM guidance is high, all drinks intakes fell below it, data not presented).

\section{Figure 1}

Bland Altman plot comparing drinks intake as assessed by the Drinks Diary and by direct observation, g/day

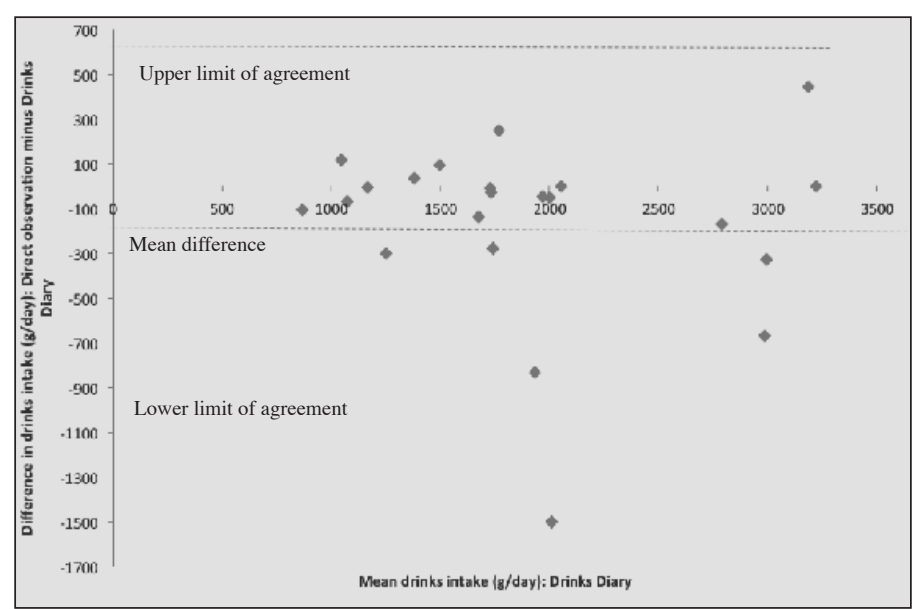

Discussion

This pilot study found that drinks intake assessed by resident-completed Drinks Diary was highly correlated with direct observation (the reference method) over 24 hours. Although burdensome for both researchers and participants, direct observation is the gold standard for dietary assessment(19). The Drinks Diary provided a useful estimation of drinks intake in more able elderly people residing in care homes. These more able residents have been found to be at high risk of dehydration as they appear independent, so staff assume they do not require help or encouragement with drinking (20) (21) .

This is the first study to ask care home residents to document their drinks intake using a drinks specific tool so there are few study comparisons. Despite the limitations of small sample size, assessment of drinks intake rather than total fluid intake, and only one 24-hour record per participant (although it is likely that accurate drinks intake assessment would require several days of observation), this study indicates that most care home residents able and willing to write (many could not take part due to cognitive or physical disabilities) completed the Drinks Diary successfully. The Drinks Diary, completed by care home residents correlated well with observed, weighed drinks intakes. We assumed that $1 \mathrm{~g}$ of drink was equivalent to $1 \mathrm{ml}$. While this is only true of water the error was considered to be minimal.

Drinks Diaries completed by care home residents performed better than staff-completed drinks intake charts, further confirming the inaccuracies of staff records (22). Poor fluid balance management and record keeping in residential care have been identified by previous researchers, with causes such as high staff turnover, lack of training and time, delays between time of drinking and recording, and not recording unconsumed drinks $(1,23,24)$. While one day is not sufficient to reliably estimate drinks intake, we were unable to conduct this small pilot study over a longer period due to resource limitations. The Drinks Diary needs further assessment and possibly development before it is used in routine practice, but provides a good starting point for further research in a variety of contexts.

The Drinks Diary may be a tool that will help draw care home residents attention to the amount that they drink, helping to combat dehydration. It may also prove useful for researchers, care staff and practitioners interested in measuring the drinks intake of elderly people.

Acknowledgments: We would like to thank the participants who completed the Drinks Diary, the managers and care staff in the care homes where the study was completed.

Conflict of interest: Florence Jimoh and Diane Bunn each declare no conflict of interest. Lee Hooper reports small grants from European Hydration Institute, non-financial support from European Hydration Institute, outside the submitted work.

Ethical Standards: The authors declare that the study procedures comply with the current ethical standards for investigation involving human participants in the United Kingdom.

Funding sources: This article presents independent research funded in part by the National Institute for Health Research (NIHR, Career Development Fellowship to Lee Hooper, NIHR-CDF-2011-04-025) and the University of East Anglia. The views expressed are those of the authors and not necessarily those of the NHS, the NIHR or the Department of Health.

\section{References}

1. Kayser-Jones J, Schell ES, Porter C, Barbaccia JC, Shaw H. Factors contributing to dehydration in nursing homes: inadequate staffing and lack of professional supervision. Journal of the American Geriatrics Society. 1999 Oct;47(10):1187-94.

2. Thomas DR, Cote TR, Lawhorne L, Levenson SA, Rubenstein LZ, Smith DA, et al. Understanding clinical dehydration and its treatment. Journal of the American Medical Directors Association. 2008 Jun;9(5):292-301.

3. Stookey JD, Purser JL, Pieper CF, Cohen HJ. Plasma hypertonicity: another marker of frailty? Journal of the American Geriatrics Society. 2004 Aug;52(8):1313-20.

4. DRIE - Dehydration Recognition in our Elders [Internet]. [cited 2013 Nov 7]. Available from: http://driestudy.appspot.com/cohort.html Accessed November 7, 2013

5. Siervo M, Bunn D, Prado C, Hooper L. Accuracy of prediction equations for serum osmolarity in frail older people with and without diabetes. Am J Clin Nutri. 2014;100(3):867-76.

6. Mentes JC. A typology of oral hydration problems exhibited by frail nursing home residents. J Gerontol Nurs. 2006 Jan;32(1):13-9; quiz 20-1.

7. Hooper L, Bunn D, Jimoh FO, Fairweather-Tait SJ. Water-loss dehydration and aging. Mech Ageing Dev. 2014 Dec 9;136(7):50-8.

8. Godfrey H, Cloete J, Dymond E, Long A. An exploration of the hydration care of older people: a qualitative study. Int J Nurs Stud. 2012 Oct;49(10):1200-11.

9. Forsyth DM, Lapid MI, Ellenbecker SM, Smith L, O'Neil M, Low D, et al. Hydration status of geriatric patients in a psychiatric hospital. Issues Ment Health Nurs. Proquest; 2008 Aug 1;29(8):853-62.

10. Pokrywka HS, Koffler KH, Remsburg R, Bennett R, Roth J, Tayback M, et al. Accuracy of patient care staff in estimating and documenting meal intake of nursing home residents. J Am Geriatr Soc. 1997;45:1223-7.

11. Folstein MF, Folstein SE, McHugh PR. "Mini-mental state". A practical method for grading the cognitive state of patients for the clinician. J Psychiatr Res. 1975 Nov;12(3):189-98.

12. Mahoney FI, Barthel DW. Functional evaluation: the Barthel Index. Md State Med J. $1965 ; 14: 61-5$.

13. EuroQol--a new facility for the measurement of health-related quality of life. Health policy (Amsterdam, Netherlands). 1990 Dec;16(3):199-208.

14. Shapiro ASS, Wilk MB. Biometrika Trust An Analysis of Variance Test for Normality ( Complete Samples ). Biometrika. 1965;52(3):591-611. 


\section{ASSESSMENT OF A DRINKS DIARY FOR USE BY THE ELDERLY}

15. Comrie F, Masson LF, McNeill G. A novel online Food Recall Checklist for use in an undergraduate student population: a comparison with diet diaries. Nutri J. 2009 Jan; $8: 13$.

16. Martin Bland J, Altman D. Statistical methods for assessing agreement between two methods of clinical measurement. The Lancet. 1986 Feb;327(8476):307-10.

17. EFSA Panel on Dietetic Products N and A (NDA). Scientific Opinion on Dietary Reference Values for water. EFSA J 2010. 2010 Mar 25;8(3):1459.

18. Institute of Medicine. Panel on Dietary Reference Intakes for Electrolytes and Water 769 Dietary Reference Intakes for Water, Potassium, Sodium, Chloride, and Sulfate. Washington, DC, USA.; 2004.

19. Thompson FE SA. Dietary assessment methodology. Second. Coulston A, Boushey C, Ferruzzi ME, editors. Nutrition in the prevention and treatment of Disease. Academic Press. San Diego; 2008
20. Mentes JC, Culp K. Reducing hydration-linked events in nursing home residents. Clin Nurs Res. 2003;12(3):210-25.

21. Gaspar PM. Water intake of nursing home residents. J Gerontol Nurs. 1999 Apr;25(4):23-9.

22. Simmons SF, Reuben D. Nutritional intake monitoring for nursing home residents: a comparison of staff documentation, direct observation, and photography methods. Journal of the American Geriatrics Society. 2000;48:209-13.

23. Chidester JC, Spangler AA. Fluid intake in the institutionalized elderly. J Am Diet Assoc. 1997;97:23-28; quiz 29-30.

24. Reid J, Robb E, Stone D, Bowen P, Baker R, Irving S, et al. Improving the monitoring and assessment of fluid balance. Nurs Times. 2004 May 18;100(20):36-9. 